\title{
KARAKTERISTIK DESAIN KAPAL BANTUAN KEMENTERIAN KELAUTAN DAN PERIKANAN DI KABUPATEN SUBANG
}

\section{Design Characteristic of Granted Ship in Subang Regency Given by Ministry of Marine and Fisheries}

\author{
Oleh: \\ Izza M Apriliani $^{1 *}$, Alexander MA Khan ${ }^{2}$, Pringgo KDNY Putra ${ }^{2}$, Pipit Fitriyani² \\ ${ }^{1}$ Program Studi Perikanan, Fakultas Perikanan dan Ilmu \\ Kelautan, Universitas Padjadjaran, Bandung, Indonesia \\ ${ }^{2}$ Program Studi Perikanan Kampus Pangandaran, Fakultas \\ Perikanan dan Ilmu Kelautan, Universitas Padjadjaran, \\ Bandung, Indonesia \\ *Korespondensi penulis: izza.mahdiana@unpad.ac.id
}

\begin{abstract}
ABSTRAK
Kementerian Kelautan dan Perikanan (KKP) memiliki program pemberian kapal bantuan penangkapan ikan kepada nelayan. Untuk mengetahui keberhasilan program pemberian kapal bantuan salah satunya dengan menganalisis karakteristik desain kapal tersebut. Tujuan dari riset ini yaitu menganalisis karakteristik desain kapal berdasarkan rasio dimensi, general arrangement dan bentuk badan kapal. Riset dilakukan dengan metode deskriptif untuk menggambarkan karakteristik desain. Pengambilan data selama bulan Februari-Mei 2021 dengan objek 6 kapal bantuan yang berbasis di Kabupaten Subang. Berdasarkan hasil riset kapal bantuan memiliki rasio dimensi yang sesuai dengan rasio dimensi kapal perikanan di Indonesia. General arrangement pada setiap jenis ukuran kapal memiliki kesamaan dalam mendukung operasi penangkapan ikan. Bentuk kasko kapal bagian depan berbentuk V-bottom, sedangkan bagian midship sampai buritan memiliki bentuk kasko kapal U-bottom, dan bentuk transom di bagian buritan. Hal tersebut sesuai dengan kebutuhan dalam mengoperasikan alat tangkap statis khususnya gillnet.
\end{abstract}

Kata kunci: bentuk kasko, dimensi utama, general arrangement, rasio dimensi

\section{ABSTRACT}

The Ministry of Maritime Affairs and Fisheries (KKP) has a granted ship program to provide fishers Intheri fishing activities. To find out the success of the granted ship program, one of them is by analyzing the design characteristics of the ship. The purpose of this research is to analyze the characteristics of the ship's design based on the dimension ratio, general arrangement and hull shape. The research was conducted using a descriptive method to describe the design characteristics. Data collection was carried out during February-May 2021 with the object of 6 granted ships based in Subang Regency. The research results show that, the granted ship has a dimension ratio that is in accordance with the dimension ratio of fishing vessels in Indonesia. The general arrangement for each type of vessel size is similar in supporting fishing operations. The hull shape of granted ship is - V-bottom in the front side, while the midship to the stern has a U-bottom shape, and transom at the end of the stern. This is in accordance to the operational need of static fishing gear, especially gillnets.

Key words: dimension ratio, hull shape, main dimensions, general arrangement

\section{PENDAHULUAN}

Potensi fishing ground yang berada di wilayah perairan Indonesia dapat dimanfaatkan dengan kegiatan operasi penangkapan ikan. Kapal yang digunakan dalam operasi penangkapan ikan merupakan salah satu yang menjadi faktor penting dalam meningkatkan hasil produksi dari operasi penangkapan ikan guna memenuhi kebutuhan masyarakat akan ikan (Palembang et al. 2013). Demi meningkatkan kebutuhan tersebut, Kementrian Kelautan dan Perikanan (KKP) pada tahun 2017 memiliki program pemberian kapal bantuan penangkapan ikan kepada nelayan. Kabupaten Subang merupakan salah satu wilayah yang memperoleh bantuan kapal penangkapan ikan. KKP berharap dengan adanya kapal bantuan tersebut, 
nelayan Kabupaten Subang dapat mengoptimalkan kegiatan penangkapan di Perairan Utara Jawa karena potensi perikanan tangkap yang besar.

Salah satu faktor yang mendukung optimalnya pemberian kapal hibah yaitu perlu mengetahui karakteristik desain yang sesuai dengan wilayah penerima. Hal tersebut dikarenakan pada setiap wilayah memiliki kebutuhan yang berbeda ditinjau dari tujuan aspek perbekalan ataupun kondisi perairan yang akan menjadi target wilayah penangkapan (fishing ground) (Fitriyashari et al. 2014). Untuk mengoperasikan alat tangkap yang sama, desain kapal perikanannya dapat berbeda bila dioperasikan pada perairan yang memiliki karakteristik oseanografi yang berbeda atau dioperasikan olen nelayan dari kelompok suku yang berbeda pula (Susanto et al. 2021).

Monitoring kapal hibah yang dilakukan Maulana (2019) menyatakan bahwa kapal bantuan KKP memiliki desain yang berbeda dengan kapal yang biasa digunakan di Pangandaran. Monitoring kapal hibah yang berbasis di Kabupaten Subang belum pernah dilakukan sebelumnya. Informasi mengenai karakteristik desain kapal akan memberikan gambaran kebutuhan operasi penangkapan secara teknis. Kebutuhan operasi penangkapan ikan tentulah memiliki perbedaan pada setiap daerah maupun setiap alat tangkap (Fyson 1985; Putra et al. 2020). Oleh karena itu, untuk mengetahui keberhasilan program pemberian kapal bantuan salah satunya dengan menganalisis karakteristik desain kapal tersebut. Tujuan dari riset ini yaitu menganalisis karakteristik desain kapal berdasarkan rasio dimensi, general arrangement dan bentuk badan kapal.

\section{METODE PENELITIAN}

Penelitian dilakukan pada bulan Februari-Mei 2021. Lokasi penelitian di Subang, Jawa Barat dengan objek penelitian kapal bantuan Kementerian Kelautan dan Perikanan (KKP). Pemilihan tempat pengambilan sampel kapal berdasarkan tempat didaratkannya kapal bantuan dari KKP yang berbasis di Subang.

Penelitian dilakukan dengan menggunakan metode deskriptif. Menurut Nazir (2002) metode deskriptif adalah suatu metode dalam penelitian suatu kondisi atau peristiwa pada masa sekarang. Tujuan dari metode deskriptif yaitu untuk membuat gambaran, secara sistematis, faktual dan akurat mengenai fakta, sifat serta hubungan fenomena yang sedang diteliti (Rukajat 2018).

Jenis data yang dikumpulkan dalam riset ini yaitu data primer dan sekunder. Pengumpulan data dilakukan melalui survei, observasi dan wawancara dengan nelayan dan pengelola kapal hibah dalam hal ini yang dimaksud adalah pihak KUD. Data primer merupakan data yang diambil langsung melalui survey lapangan (Pakadang 2013). Data primer berupa pengukuran kapal, alat tangkap dan tata letak diatas kapal. Data sekunder berupa data jumlah kapal, surat ukur kapal yang diperoleh dari Dinas Kelautan dan Perikanan (DKP) Kabupaten Subang serta studi pustaka. Data yang terkumpul selanjutnya digunakan untuk membuat general arrangement kapal dan dihitung rasio dimensinya yang nantinya dibandingkan dengan hasil penelitian Iskandar dan Pujiati (1995).

\section{HASIL DAN PEMBAHASAN}

Kementerian Kelautan dan Perikanan (KKP) sejak tahun 2016-2017 telah memberikan kapal bantuan untuk Kabupaten Subang sebanyak 11 unit kapal. Jumlah kapal bantuan KKP yang diukur dalam penelitian ini sebanyak 6 unit dari jumlah keseluruhan kapal bantuan dikarenakan 5 unit kapal bantuan sudah dialihkan ke Provinsi Gorontalo. Spesifikasi kapal bantuan di Kabupaten Subang dapat dilihat pada Tabel 1.

Tabel 1 menunjukkan spesifikasi dimensi utama kapal bantuan KKP di Kabupaten Subang. Kapal ukuran 25 GT memiliki nilai LOA sebesar 17,4 m, LDL sebesar 16,74 m, B atau lebar maksimum sebesar $3,55 \mathrm{~m}$, serta nilai D atau dalam sebesar 1,84 m. Nilai spesifikasi dimensi utama kapal bantuan KKP ukuran 13 GT memiliki nilai LOA atau panjang total sebesar 13,50-13,57 m dengan rata-rata 13,53 m. Nilai LDL sebesar 13,20 m. Nilai B atau lebar maksimum sebesar 2,75-2,76 m dengan rata-rata 2,75 m, serta nilai D atau dalam sebesar $1,55 \mathrm{~m}$.

Nilai spesifikasi dimensi utama kapal bantuan KKP ukuran 6 GT memiliki nilai LOA atau panjang total sebesar 10,58-10,60 m dengan rata-rata 10,59 m. Nilai LDL sebesar 9,50 m. Nilai B atau lebar maksimum sebesar 2,62-2,65 m dengan rata-rata 2,63 m, serta nilai $\mathrm{D}$ atau dalam sebesar $0,94-0,97 \mathrm{~m}$ dengan rata-rata $0,96 \mathrm{~m}$. 
Tabel 1 Spesifikasi Kapal Bantuan KKP di Kabupaten Subang

\begin{tabular}{cccccccccc}
\hline \multirow{2}{*}{ No } & \multirow{2}{*}{ Nama Kapal } & \multicolumn{1}{c}{ Spesifikasi Ukuran Kapal (m) } & \multicolumn{1}{c}{ Ukuran } \\
\cline { 3 - 7 } & KM.Nelayan 2016-29 & 17,14 & 16,74 & 3,55 & 1,84 & 5,45 & 2,50 & 2,00 & 25 \\
\hline 1 & KM. & LDL & B & D & Pb & Lb & Tb & GT \\
2 & KM.Nelayan 2017-821 & 13,50 & 13,20 & 2,75 & 1,55 & 3,91 & 2,15 & 1,97 & 13 \\
3 & KM.Nelayan 2017-820 & 13,57 & 13,20 & 2,76 & 1,55 & 3,95 & 2,09 & 1,95 & 13 \\
4 & KM.Nelayan 2017-557 & 10,60 & 9,50 & 2,62 & 0,97 & 3,65 & 1,50 & 1,52 & 6 \\
5 & KM.Nelayan 2017-558 & 10,58 & 9,50 & 2,65 & 0,94 & 3,67 & 1,53 & 1,50 & 6 \\
6 & KM.Nelayan 2017-556 & 10,60 & 9,50 & 2,64 & 0,98 & 3,62 & 1,52 & 1,49 & 6 \\
\hline
\end{tabular}

Keterangan:

$\begin{array}{ll}\mathrm{LOA} & =\text { Lenght Over All } \\ \mathrm{LDL} & =\text { Length Deck Line } \\ \mathrm{B} & =\text { Breadth maksimum } \\ \mathrm{D} & =\text { Depth } \\ \mathrm{Pb} & =\text { Panjang bangunan diatas dek } \\ \mathrm{Lb} & =\text { Lebar bangunan diatas dek } \\ \mathrm{Tb} & =\text { Tinggi bangunan diatas dek }\end{array}$

\section{Rasio Dimensi Utama}

Rasio dimensi utama kapal dapat mencerminkan karakteristik performa dari sebuah kapal yang meliputi stabilitas, kemampuan olah gerak serta kekuatan memanjang kapal. Berdasarkan Istiqomah et al. (2014) menyatakan bahwa kapal yang memiliki performa yang lebih baik dipengaruhi oleh rasio dimensi utama yang ideal. Rasio dimensi merupakan nilai perbandingan antara panjang dan lebar (L/B), perbandingan antara panjang dan dalam (L/D) serta perbandingan lebar dan dalam (B/D).

Rasio dimensi utama dihitung berdasarkan perbandingan nilai yang telah tertera pada Tabel 1. Hasil perhitungan tersebut selanjutya akan dibandingkan dengan nilai rasio pembanding untuk kapal perikanan di Indonesia berdasarkan Iskandar dan Pujiyati (1995). Alat tangkap yang digunakan oleh kapal bantuan KPP di Kabupaten Subang yaitu alat tangkap gillnet. Alat tangkap tersebut merupakan jenis alat tangkap dengan metode pengoperasian static gear. Hasil perhitungan rasio dimensi utama kapal bantuan KKP di Kabupaten Subang dibandingkan dengan rasio dimensi kapal yang mengunakan metode static gear. Perbandingan nilai rasio L/B, L/D, B/D kapal bantuan KKP yang berbasis di Kabupaten Subang dapat dilihat pada Tabel 2.

Tabel 2 Hasil Perhitungan Rasio Dimensi Utama Kapal Bantuan KKP

\begin{tabular}{ccccc}
\hline No & Nama Kapal & L/B & L/D & B/D \\
\hline 1 & KM. Nelayan 2016-29 & 4,83 & 9,32 & 1,93 \\
2 & KM. Nelayan 2017-821 & 4,91 & 8,71 & 1,77 \\
3 & KM. Nelayan 2017-820 & 4,92 & 8,75 & 1,78 \\
4 & KM. Nelayan 2017-557 & 4,05 & 10,93 & 2,70 \\
5 & KM. Nelayan 2017-558 & 3,99 & 11,26 & 2,82 \\
6 & KM. Nelayan 2017-556 & 4,02 & 10,82 & 2,69 \\
\hline & Nilai Minimum & 3,99 & 8,71 & 1,77 \\
& Nilai Maksimum & 4,92 & 11,26 & 2,82 \\
& Rata-Rata & $3,99-4,92$ & $8,71-11,26$ & $1,77-2,82$ \\
& Iskandar dan Pujiati (1995) & $2,83-11,12$ & $4,58-17,28$ & $0,96-4,68$ \\
\hline
\end{tabular}

Rasio L/B kapal bantuan KKP pada ketiga ukuran yaitu 6, 13 dan 25 GT berada didalam kisaran nilai rasio pembanding Iskandar dan Pujiati (1995). Kapal bantuan KKP memiliki nilai rasio L/B yang mendekati kisaran minimum nilai rasio pembanding. Hal ini mengindikasikan bahwa kapal bantuan yang berbasis di Kabupaten Subang memiliki olah gerak yang baik namun akan berdampak negatif terhadap kecepatan kapal. Berdasarkan Setiawan et al. (2021) menyatakan apabila nilai L/B semakin kecil maka akan berpengaruh buruk terhadap kecepatan kapal karena nilai tahanan geraknya akan semakin besar. Kondisi tersebut disesuaikan dengan kebutuhan kapal yang mengoperasikan alat tangkap statis sehingga lebih mengutamakan stabilitas dan kapasitas muat dibandingkan kecepatannya (Susanto et al. 2021). Adanya kondisi olah gerak kapal yang baik pada kapal tersebut sehingga kapal tidak mengalami modifikasi 
penambahan katir yang berfungsi untuk menjaga kestabilan kapal seperti kapal bantuan KKP di Kabupaten Pangandaran dan Kabupaten Sukabumi (Nirmalasari et al. 2020).

Nilai rasio L/D dari ketiga ukuran kapal bantuan KKP yang berbasis di Kabupaten Subang berada pada kisaran nilai rasio dimensi kapal pembanding Iskandar dan Pujiati (1995). Kondisi ini menunjukkan bahwa kapal tersebut memiliki kekuatan memanjang yang baik. Nilai ini juga sama dimiliki oleh kapal hibah yang berbasis di Kabupaten Pangandaran bahwa kapal hibah memiliki kekuatan longitudinal yang baik (Apriliani et al. 2019). Kondisi ini bertujuan agar kapal tetap kuat walaupun menghadapi kondisi gelombang yang tinggi dan tetap aman selama proses operasi penangkapan ikan (Susanto et al. 2021). Berdasarkan nilai perbandingan L/D, kapal bantuan KKP yang berbasis di Kabupaten Subang menunjukan bahwa semakin besar nilai L/D yang dihasilkan maka daya dorong yang dihasilkan akan semakin besar tetapi stabilitasnya semakin menurun.

Nilai rasio B/D kapal bantuan KKP berukuran 6, 13 dan 25 GT berada didalam kisaran nilai rasio pembanding. Nilai rasio B/D pembanding yang digunakan untuk kapal static gear yaitu berkisar antara 0,96 hingga 4,68. Rata-rata nilai rasio dimensi B/D kapal bantuan KKP yang berukuran 6, 13 dan 25 GT secara berurutan adalah 2,74, 1,78 dan 1,93. Perbandingan dimensi B/D kapal ukuran 13 dan 25 GT menunjukkan nilai yang lebih kecil dibandingkan dengan kapal ukuran 6 GT. Hal tersebut menunjukan kapal ukuran 6 GT memiliki stabilitas yang lebih baik dan daya dorong yang semakin berkurang dibandingkan dengan kapal bantuan berukuran 13 dan 25 GT. Kapal ukuran 13 dan 25 GT memiliki nilai rasio dimensi cenderung kecil mendekati ambang batas bawah nilai rasio pembanding. Kecilnya nilai B/D juga berdampak terhadap besarnya nilai daya dorong yang dialami kapal sehingga berdampak terhadap penurunan kondisi stabilitas kapal.

\section{General Arrangement Kapal}

General arrangement merupakan gambar yang menunjukan kelengkapan ruang kapal secara umum yang dilihat dari atas dan samping kapal (Fajrin dan Jaya 2018). Kapal bantuan yang diukur selama observasi lapangan yaitu KM. Nelayan 2017-556 untuk ukuran 6 GT, KM. Nelayan 2017-820 ukuran 13 GT dan KM. Nelayan 2016-29 ukuran 25 GT. General arrangement kapal bantuan dapat dilihat pada Gambar 1-3.

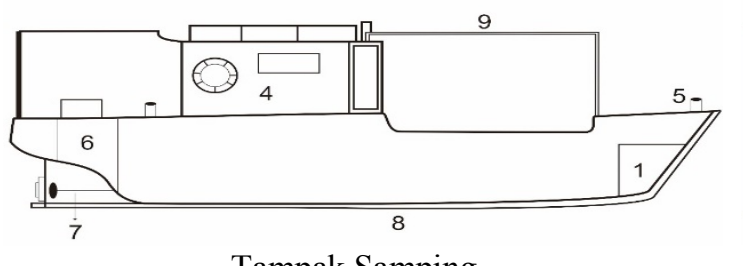

Tampak Samping

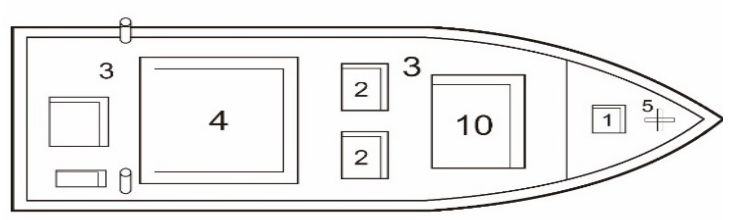

Tampak Atas

Gambar 1 General Arrangement KM. Nelayan 2017-556 ukuran 6 GT

Keterangan:
1. Ruang ballast
2. Palka
3. Dek atau geladak
4. Ruang kemudi
5. Tiang tali jangkar

$\begin{array}{cl}\text { 6. } & \text { Ruang mesin } \\ \text { 7. } & \text { Kemudi kapal } \\ \text { 8. } & \text { Lunas } \\ \text { 9. } & \text { Tiang } \\ \text { 10. } & \text { Ruang penyimpanan alat tangkap }\end{array}$

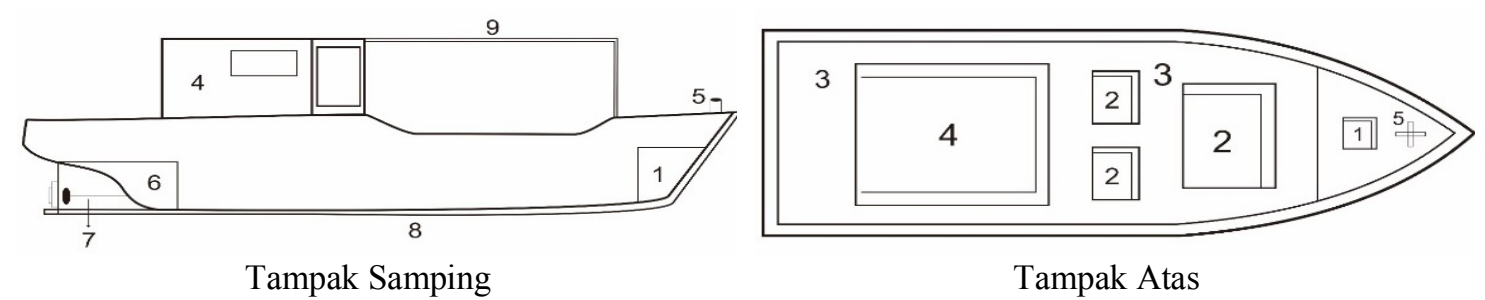

Gambar 2 General Arragement KM. Nelayan 2017-820 Ukuran 13 GT

Keterangan:
1. Ruang ballast
6. Ruang mesin 
2. Palka

3. Dek atau geladak

4. Ruang kemudi

5. Tiang tali jangkar
7. Kemudi kapal

8. Lunas

9. Tiang

10. Ruang penyimpanan alat tangkap

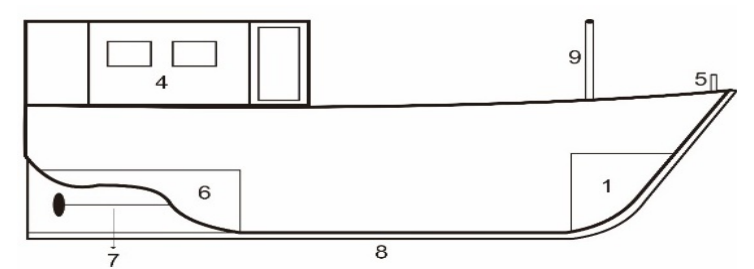

Tampak Samping

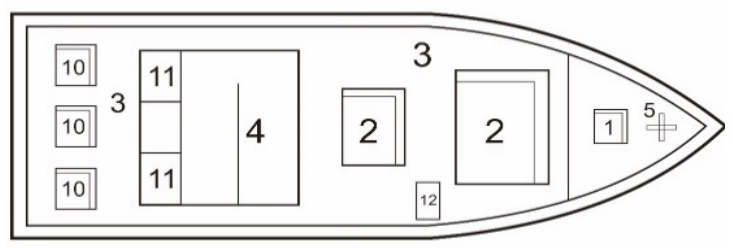

Tampak Atas

Gambar 3 General Arragement KM. Nelayan 2016-29 Ukuran 25 GT

Keterangan:

1. Ruang ballast

2. Palka

3. Dek atau geladak

4. Ruang kemudi

5. Tiang tali jangkar

\author{
6. Ruang mesin \\ 7. Kemudi kapal \\ 8. Lunas \\ 9. Tiang \\ 10. Ruang penyimpanan alat tangkap
}

\title{
Bentuk Badan Kapal
}

Berdasarkan bentuk body plan pada Gambar 4 dapat diketahui bahwa seluruh ukuran kapal bantuan memiliki kasko kapal bagian depan berbentuk V-Bottom, sedangkan bagian midship sampai buritan memiliki bentuk kasko kapal U-Bottom. Berdasarkan Murhum et al. (2020) menyatakan bahwa bentuk VBottom pada haluan kapal berfungsi untuk membelah massa air sehingga kapal memiliki kecepatan tinggi sedangkan bentuk U-Bottom pada bagian midship sampai buritan kapal bertujuan agar kapal memiliki olah gerak yang baik.

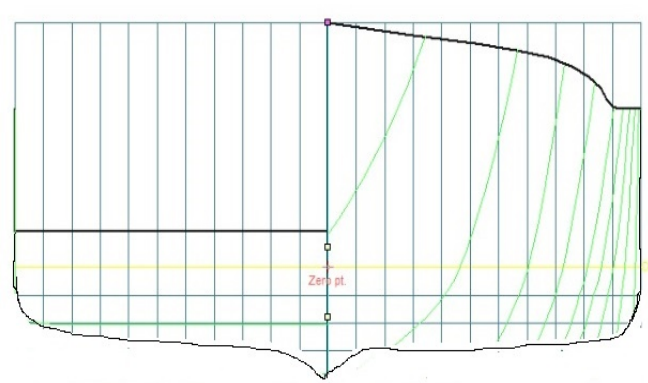

(a)

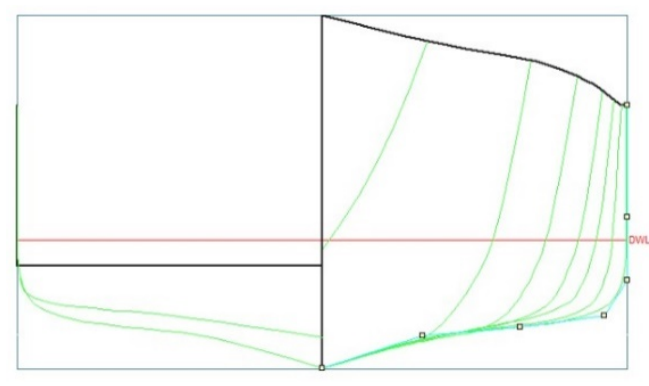

(b)

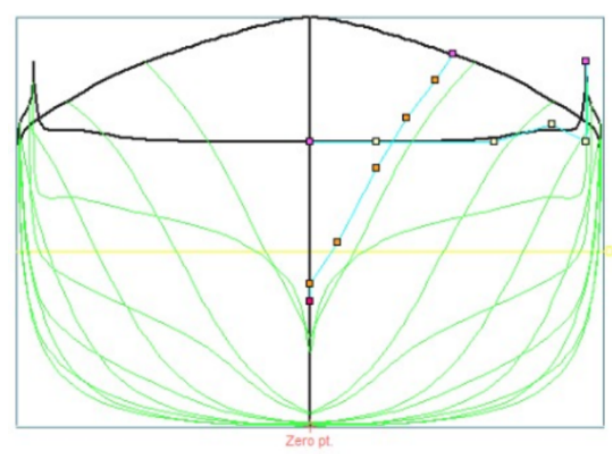

(c)

Gambar 4 Body Plan Kapal

KM. Nelayan 2017-556 (b) KM. Nelayan 2017-820 (c) KM. Nelayan 2016-29 
Novita dan Iskandar (2008) menyatakan bahwa pada kapal yang mengoperasikan alat tangkap yang tidak memprioritaskan kecepatan dalam pengoperasiannya (handline, longline, gillnet dan trap), maka bentuk U-bottom sudah sesuai untuk digunakan. Dengan demikian, berdasarkan bentuk midship kapal bantuan KKP sudah sesuai dengan peruntukkannya dalam mendukung operasi penangkapan menggunakan alat tangkap gillnet. Berdasarkan bentuk tampak atas (Gambar 1-3), semua ukuran kapal bantuan KKP memiliki bentuk badan berupa bentuk transom. Bentuk kapal transom memiliki bentuk buritan yang lebar. Bentuk buritan kapal berkaitan erat dengan efektivitas daun kemudi untuk mengendalikan arah kapal (Susanto et al. 2021).

\section{KESIMPULAN DAN SARAN}

Kapal bantuan KKP yang berbasis di Kabupaten Subang memiliki rasio dimensi yang sesuai dengan rasio dimensi kapal perikanan di Indonesia. General arrangement di ketiga ukuran memiliki kesamaan dalam mendukung operasi penangkapan ikan. Bentuk kasko kapal bagian depan berbentuk V-bottom, sedangkan bagian midship sampai buritan memiliki bentuk kasko kapal U-bottom. Bentuk kapal tampak atas berbentuk transom. Hal tersebut sesuai dengan kebutuhan dalam mengoperasikan alat tangkap statis khususnya gillnet.

\section{DAFTAR PUSTAKA}

Apriliani IM, Dewanti LP, Herawati H, Riyantini I, dan Maulana M. 2019. Analisis Teknis Kapal Hibah yang Berbasis di Pangandaran Berdasarakan Standar Biro Klasifikasi Indonesia (BKI). ALBACORE Jurnal Penelitian Perikanan Laut. 3(3): 235-240.

Fajrin RA dan Jaya I. 2018. Perbandingan Desain Kapal Purse Seine yang Dioperasikan di Selat Makassar dengan Kapal Purse Seine yang Dioperasikan Laut Flores. Prosiding Simposium Nasional Kelautan dan Perikanan, (5).

Fitriyashari A, Rosyid A, Ayunita D. 2014. Analisis Kebutuhan Perbekalan Kapal Penangkap Ikan di Pelabuhan Perikanan Pantai Tasikagung, Rembang. Journal of Fisheries Resources Utilization Management and Technology. 3(3):122-130.

Fyson J. 1985. Design of Small Fishing Vessels. England (UK): Fishing News Book.

Iskandar BH dan Pujiati S. 1995. Keragaan Teknis Kapal Perikanan di Beberapa Wilayah Indonesia (Laporan Penelitian). Bogor (ID): Jurusan Pemanfaatan Sumberdaya Perikanan FPIK IPB.

Istiqomah I, Susanto A dan R Irnawati. 2014. Karakteristik Dimensi Utama Kapal Jaring Rampus di Pelabuhan Perikanan Nusantara Karangantu Kota Serang Provinsi Banten. Jurnal Perikanan dan Kelautan. 4(4): 269-276.

Maulana M. 2019. Kesesuaian Kapal Hibah Kementerian Kelautan dan Perikanan yang Berbasis di Pangandaran. Skripsi. Sumedang (ID): FPIK Unpad.

Murhum KSO, Anadi L, Abdullah. 2020. Pengaruh Bentuk Kasko Terhadap Tahanan dan Kecepatan Kapal Bantuan Kementrian Kelautan Dan Perikanan (Kasus Kapal Fiberglass 5 GT Tahun 2017). Jurnal Manajemen Sumber Daya Perairan. 5(2), 118-129.

Nazir M. 2002. Metode Analisis Deskriptif. Yogyakarta (ID): Erlangga.

Nirmalasari D, Apriliani IM, Supriadi D dan Khan AMA. (2020). Suitabilty of Gross Tonnage of Grant Fishing Vessel by Kementrian Kelautan dan Perikanan Based in Sukabumi. Global Scientific Journal. 8(5): 400-408.

Novita Y dan Iskandar BH. 2008. Hubungan antara Bentuk Kasko Model Kapal Ikan dengan Tahanan Gerak. Buletin PSP. 17(3): 315-324.

Pakadang D. 2013. Evaluasi Penerapan Sistem Pengendalian Intern Penerimaan Kas pada Rumah Sakit Gunung Maria di Tomohon. Jurnal EMBA: Jurnal Riset Ekonomi, Manajemen, Bisnis dan Akuntansi. 1(4): 213-223. 
Palembang S, Luasunaung A dan Pangalila FP. 2013. Kajian Rancang Bangun Kapal Ikan Fibreglass Multifungsi 13 GT di Galangan Kapal CV Cipta Bahari Nusantara Minahasa Sulawesi Utara. Jurnal Ilmu dan Teknologi Perikanan Tangkap. 1(3): 87-92.

Putra PKDNY, Novita Y, Iskandar BH. 2020. Keragaman Bentuk Kapal Penangkap Ikan yang Berbasis di Pelabuhan Perikanan Nusantara Brondong. Saintek Perikanan: Indonesian Journal of Fisheries Science and Technology. 16(4): 235-242.

Rukajat A. 2018. Pendekatan Penelitian Kuantitatif. Yogyakarta (ID): Deepublish. $160 \mathrm{hlm}$.

Setiawan FH, Supeni EA dan Wahab AA. 2021. Pengaruh Rasio Dimensi Utama Terhadap Stabilitas Kapal Purse Seine di Kecamatan Kusan Hilir (Studi Kasus Kapal Purse Seine KM. Bangun Polea 01). Jurnal Riset Kapal Perikanan. 1(1): 17-23.

Susanto A, Novita Y, Nurdin HS, Dariansyah MR, Heriawan Y, Supiyono I, Rokhman MS. 2021. Karakteristik Desain Kapal Static Gear di Selat Sunda. Jurnal Riset Kapal Perikanan. 1(2): 67-74. 